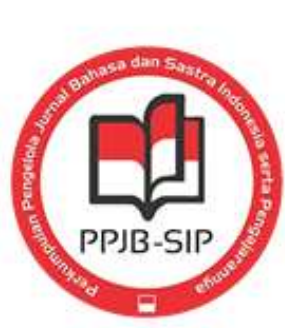

Bahasa: Jurnal Keilmuan Pendidikan Bahasa dan Sastra Indonesia

Journal Homepage:

https://jurnal.ppjb-sip.org/index.php/bahasa/index

E-ISSN: $2685-4147$

\title{
GHOST MIGRATION IN PLAYSTORE: MYSTERY REPRODUCTION AND AESTHETIC RESISTANCE
}

\section{MIGRASI HANTU DALAM PLAYSTORE: REPRODUKSI MISTERI DAN ESTETIKA RESITENSI}

\author{
Dwi Susanto ${ }^{1}$ \\ ${ }^{1}$ Universitas Sebelas Maret \\ email: dwisastra81@gmail.com
}

\begin{abstract}
Mystery story genre, such as ghost story, have migrated in virtual media or digital media, exspecially Playstore. The migration caused many modifications and adptation, that convert with digital media. This paper aims to show ghost story in Playstore aplication, the response reader, and the ghost story as aesthetic discourse pratical. The data of this paper are ghost stories in Playstore, response readers, and narartion which is related with aesthetic discourse. The interpretation data use sosiological perspective. This paper result that the ghost story migration in virtual media have changed image and representation ghost stories became metropolit. It changes the oppsite between tradition versus modern. The response reader appears that this genre is habitual and popular in thier horizon expecation as information and entertaiment. The simbolic reproduction show that the mystery world create pleasure, entertaiment, and other mystery. It is resistance toward canonical aesthetic and mystery genre itself, which eliminated by dominan aesthetic.
\end{abstract}

Keywords: story, symbolic reproduction, and virtual literature

\begin{abstract}
Genre cerita misteri, seperti cerita hantu, telah bermigrasi di media virtual atau media digital, khususnya Playstore. Migrasi tersebut menyebabkan banyak modifikasi dan adptasi, yang dikonversi dengan media digital. Makalah ini bertujuan untuk menunjukkan cerita hantu dalam aplikasi Playstore, respons pembaca, dan cerita hantu sebagai wacana estetika yang praktis. Data dari makalah ini adalah cerita hantu di Playstore, respons pembaca, dan narartion yang terkait dengan wacana estetika. Data interpretasi menggunakan perspektif sosiologis. Makalah ini menghasilkan bahwa migrasi cerita hantu di media virtual telah mengubah gambar dan representasi cerita hantu menjadi metropolitan. Ini mengubah oppsite antara tradisi versus modern. Melalui respons pembaca terlihat bahwa genre ini adalah kebiasaan dan populer dalam harapan cakrawala mereka sebagai informasi dan hiburan. Reproduksi simbolik menunjukkan bahwa dunia misteri menciptakan kesenangan, hiburan, dan misteri lainnya. Ini adalah perlawanan terhadap estetika kanonik dan genre misteri itu sendir, yang dihilangkan oleh estetika dominan.
\end{abstract}

Kata kunci: cerita, reproduksi simbolik, dan sastra virtual

Received 09-04-2020, Accepted 16-05-2020

https:doi.org/10.26499/bahasa.v2i3.50

Published By: Perkumpulan Pengelola Jurnal Bahasa dan Sastra Indonesia (PPJB-SIP) 

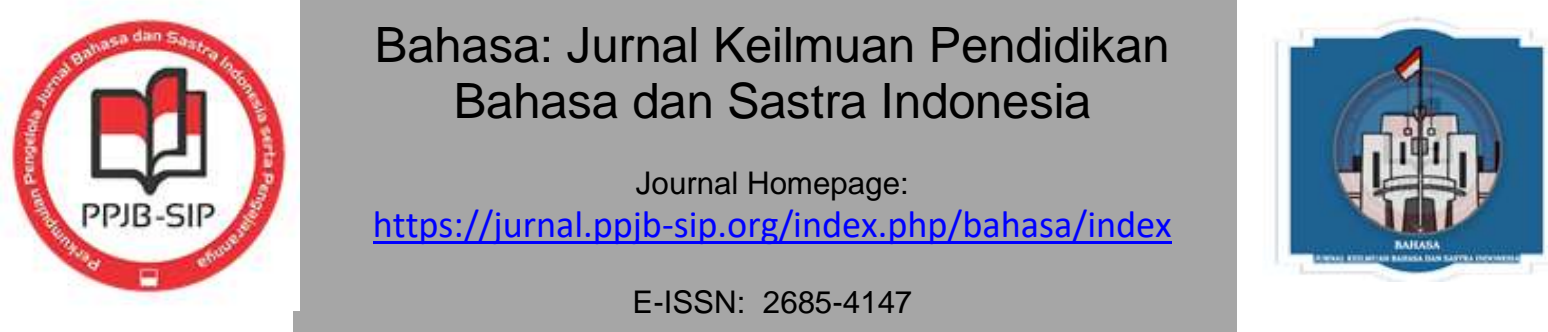

\section{PENDAHULUAN}

Keberadaan sastra virtual, siber, elektronik, hingga digital memang tidak perlu diperdebatkan kelayakan hadir ataupun kualitasnya. Sudah saatnya para peneliti mempertimbangkan bukan hanya kualitas ataupun dampaknya bagi kesastraan konvensional, tetapi hal yang sesungguhnya ditampilkan oleh fenomena itu. Artinya, perhatian pada sastra siber atau sastra virtual sudah seharusnya mengarah pada persoalan dampak terhadap pembaca ataupun isu-isu sosiologis hingga kultural yang muncul di balik fenomena itu. Bahkan, ada sebagian peneliti yang menggabungkan antara teks manual dengan digital untuk sebuah proyek yang disebut dengan xenotext, yakni melihat genetika dan DNA melalui tampilan bahasa dalam media digital, terutama kesastraan (Bok, 2011).

Sastra virtual terutama cerita hantu, seperti kuntilanak ataupun sejenisnya di dalam konteks dunia digital masyarakat Indonesia menunjukkan sebuah fenomena yang mengagumkan. Fenomena itu dapat dilihat dari jumlah sastra virtual, genre atau jenis, dan media untuk menampilkan jenis tersebut, seperti laman, video, ataupun aplikasi, baik yang berbayar maupun gratis, dalam kemasan teknologi android. Dari sisi jenis, sastra mistik atau misteri dapat menampilkan berbagai hal seperti ruang simbolik kultural, resistensi pada estetika atau genre yang dominan, dan aspek resepsi pembaca yang jumlahnya cukup banyak.

Sebagai contoh dari fenomena itu, sastra atau cerita misteri dari tradisi lokal, terutama masyarakat Jawa, seperti kuntilanak, pocong, gGenderuwo, dan lain-lain sering diabaikan dan tidak pernah dilihat sebagai satu produk kultural kesastraan. Padahal, cerita tersebut mengakar dalam kehidupan masyarakat Jawa yang kini telah bermigrasi dalam dunia digital melalui sastra virtual. Sebagai contoh, bila dalam laman pencaharian Google diketik dengan kata kunci kuntilanak, laman Google tersebut akan menunjukkan jumlah yang mengagumkan mengenai kuntilanak, seperti berita tentang kuntilanak, film kuntilanak, hingga laman yang bercerita tentang kuntilanak. Bahkan, Playstore juga menunjukkan berbagai aplikasi atau program yang berhubungan dengan kuntilanak atau hantu, seperti game, film dan buku , musik , suara , ringtone , kumpulan foto , dan lain-lain mengenai kuntilanak. Sementara itu, aplikasi Playstore juga menampilakan puluhan cerita horor yang ada cerita kuntilanak, seperti "Cerita Horror True Story", "1000+ Cerita Hantu Horor Terbaru", "1000+ Cerita Hantu Horor Seram”, "Cerita Hantu Horor Seram", "Suara Hantu: Pocong Kuntilanak", “600+ Cerita Hantu: Cerita Hantu Seram”, "Cerita Hantu Nyata Seram", "Pocong Ghost \& Kuntilanak: Horror, Cerita Horor", dan lain-lainlain.

Penelitian yang berhubungan dengan topik sastra digital ataupun sastra virtual ini telah banyak dilakukan. Penelitian-penelitian tersebut di antaranya mempersoalakan dampak sastra virtual terhadap sastra konvensional, kualitas dan kuantitas karya sastra virtual, hingga pandangan yang mengatakan positif dan negatif atas kehadiran sastra virtual tersebut (Herfanda, 2004; Suprihatin, 2012; Septriani, 2016). Namun, ada juga yang berusaha melihat fenomena tersebut dari sisi ekonomi atau sastra virtual sebagai produk industry, seperti tulisan Mawardi

Received 09-04-2020, Accepted 16-05-2020

https:doi.org/10.26499/bahasa.v2i3.50

Published By: Perkumpulan Pengelola Jurnal Bahasa dan Sastra Indonesia (PPJB-SIP) 

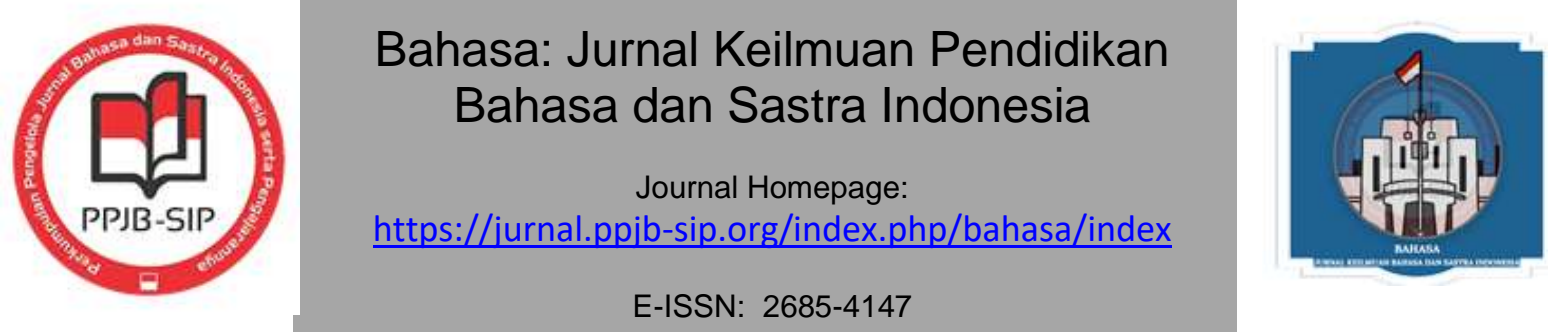

(2018) tentang cyber wattpadd pada penerbit indie. Sementara itu, penelitian mengenai keberadaan sastra siber juga ada yang dihubungkan dengan kesehatan tubuh dan kehidupan mental dalam dunia digital seperti yang dikemukan oleh Bouchardon dan Lopez-Varela (2011) serta Zalbidea dan Sotelo (2014).

Dari beberapa penelitian itu menunjukkan bahwa dari berbagai sisi, kehadiran sastra virtual menjadi bagian yang tidak bisa dipisahkan dari kehidupan sosial dan kultural hingga politik. Ada satu contoh penelitian yang cukup menarik terhadap ekstensi dari sastra virtual tersebut. Penelitian itu dilakukan oleh Holckx (2004) yang mengemukan peran komunitas puisi virtual di Cina. Menurut komunitas puisi virtual di Cina, mengembangkan sebuah gagasan terselubung melalui bahasa sekaligus menghindari sensor dari pemerintah Cina. Selain itu, komunitas puisi virtual tersebut menjadi agen dalam melakukan reproduksi simbolik tentang identitas kecinaan yang berbeda dengan narasi pemerintah atau penguasa. Dari hal ini tampak keberadaan sastra virtual sudah tidak layak untuk dilihat dari kualitas estetika tekstualnya, tetapi sebagai bagaian integral dalam komunikasi dan realitas sosial dan kebudayaan hingga politik.

Sementara itu, kehadiran cerita hantu dengan berbagai variasinya dalam Playstore menunjukkan beberapa hal yang unik. Hal utama yang menjadi persoalan untuk dilihat adalah gagasan yang terepresentasi dari kehadiran genre tersebut. Hal ini dapat dilihat dari tiga hal. Pertama, selain membawa gagasan komersial, jenis sastra tersebut banyak yang mengunduh. Artinya, hal ini menunjukkan bahwa keterbacaan yang cukup tinggi sehingga "tampilan" dan isi formal dari genre cerita hantu menjadi bagian yang menarik untuk dilihat. Kedua, aspek-aspek sosiologis muncul dalam cerita jenis ini, yang dapat dilihat dari sisi respons pembaca yang ditunjukkan melalui kepopuleran dan reviewer pembacanya. Respons ini dihubungkan dengan tingkat narasi dan isi cerita untuk mengetahui gagasan sosiologis yang ditampilkan. Ketiga, kehadiran genre ini menunjukkan migrasi ke dalam wilayah metropolitan sehingga wacana estetika atas kehadiran genre in menjadi satu masalah yang perlu dilihat.

Kehadiran sebuah genre dalam konstelasi wacana estetika dapat dilihat dari berbagai sisi, yang salah satunya adalah sisi sosiologis. Gagasan mengenai tata naratif menyimpan tujuan atau kelompok sosial hingga ideologi telah dibahas secara luas oleh Ian Watt. Namun, persoalan antara teks atau material dengan kehidupan sosial khusus wacana genre tersebut merupakan bagian dari sosiologi sastra atau sosiologi seni. Sementara itu, sosiologi seni dapat dianggap sebagai induk dari culture studies. Dalam hal ini, ada beberapa perhatian yang perlu dikemukan, yakni produk sosial dan konsumsinya. Hal yang utama menjadi perhatian adalah tentang kehidupan sosial dan sosial teks itu (Wolff, 2005: 89).

Berdasarkan gagasan tersebut, kehidupan sosial merupakan sesuatu yang real dan menjadi bagian dari struktur masyarakat. Sementara itu, kehidupan teks lebih difokuskan pada teks tersebut ditempatkan dalam kehidupan sosial atau struktur sosial, yakni struktur masyarakat. Dalam konteks genre cerita hantu ini, genre dapat dipandang sebagai sebuah tindakan kolektif pemilik genrenya (Becker, 1974). Tindakan kolektif itu dapat diketahui dari tata naratif, respons

Received 09-04-2020, Accepted 16-05-2020

https:doi.org/10.26499/bahasa.v2i3.50

Published By: Perkumpulan Pengelola Jurnal Bahasa dan Sastra Indonesia (PPJB-SIP) 

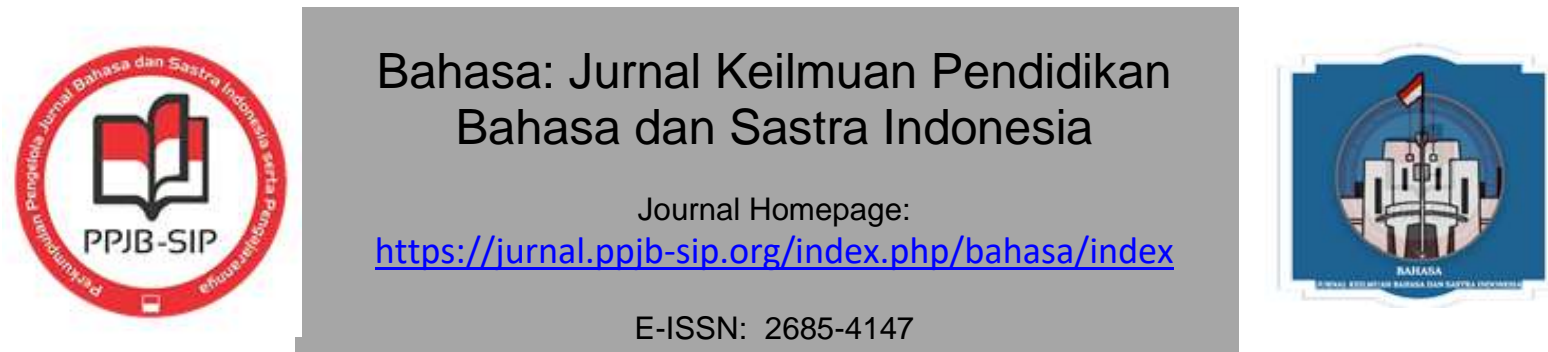

pembaca, dan juga wacana estetika yang melingkupinya sebagai satu praktik sosial bersama. Artinya, meskipun praktik sosial itu dipandang memiliki dampak yang kecil bagi wacana atau struktur yang dominan, pengaruh yang terus meneurus atas praktik sosial bersama itu mampu mengubah struktur melalui sebuah resistensi sebagai wujud praktik sosial atas wacana yang dominan.

a. Hal yang sangat memungkinkan dari keadaan itu adalah penciptaan sebuah struktur yang baru dan bersinggungan dengan struktur lama ataupun seakan berdampingan dengan struktur yang lama. Hal ini dilakukan melalui penciptaan sebuah kehidupan genre sebagai tindakan bersama suatu kelompok. Dia bisa menjadi semacam akomodsai ataupun sekaligus menjadi resistensi atas struktur kanon yang ingin ditempati atau ditembus. Dalam kasus ini, praktik tersebut muncul dalam penciptaan genre misteri, seperti cerita hantu..

\section{METODE PENELITIAN}

Penelitian ini merupakan penelitian kualitatif. Data berupa tata naratif dan tampilan dari cerita hantu yang berada dalam aplikasi Playstore yang dipilih beberapa cerita. Selain itu, data yang lainnya adalah respons pembaca dan wacana estetika yang mendominasinya hingga keberadaan genre dalam strukrur sosial. Struktur sosial dalam konteks ini adalah struktur kesastraan. Atinya, sastra ditempatkan dalam konteks wacananya. Sumber data diperoleh melalui cerita hantu dari aplikasi Playstore dan berbagai artikel atau tulisan yang berhubungan dengan topik tulisan ini. Teknik interpretasi data dilakukan dengan model pembacaan yang melingkar. Pertama, tampilan atau isi tata naratif dibaca dan ditemukan. Selanjutnya, kedua, respons dari pembaca atas tampilan dan tata naratif yang dikemukan. Kemudian, ketiga, hubungan antara tampilan dan respons pembaca tersebut direduksi melalui sebuah gagasan tentang keberadannya dalam konteks struktur sosial, yakni struktur dalam kesastraan atau keberadaan genre itu.

\section{ANALISIS DAN PEMBAHASAN}

\section{Sastra Virtual Hantu dalam Playstore}

Genre mistik atau misteri pada awalnya muncul dalam khazanah kesastraan Barat, seperti cerita tentang drakula ataupun vampir. Cerita tersebut berhubungan dengan kemunculan gagasan sastra romantik atau gotik. Hantu atau misteri dalam khazanah masyarakat Jawa tidak berhubungan dengan aliran romantik atau gotik seperti dalam khazanah sastra Eropa. Namun, keberadaannya sangat mungkin diasumsikan sebagai bagian dari kepercayaan atau tradisi masyarakat setempat. Biasanya, hantu dihubungkan dengan arwah orang meninggal, meskipun hal itu tidak sepenuhnya benar. Selain itu, kepercayaan masyarakat yang mengungkapkan bahwa dalam dunia ini ada alam lain yang dihuni makhluk ciptaan Tuhan dan agama Islam sebagai agama mayoritas turut mengajarkan hal itu.

Received 09-04-2020, Accepted 16-05-2020

https:doi.org/10.26499/bahasa.v2i3.50

Published By: Perkumpulan Pengelola Jurnal Bahasa dan Sastra Indonesia (PPJB-SIP) 


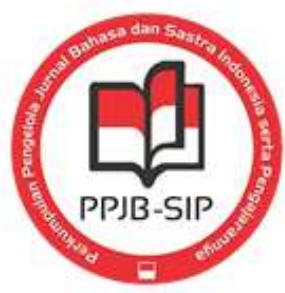

\section{Bahasa: Jurnal Keilmuan Pendidikan Bahasa dan Sastra Indonesia \\ Journal Homepage: \\ https://jurnal.ppjb-sip.org/index.php/bahasa/index \\ E-ISSN: $2685-4147$}

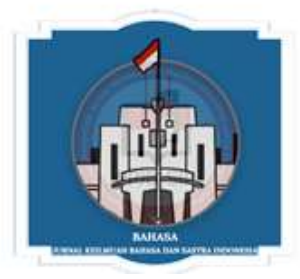

Migrasi cerita hantu ke dalam Playstore bukanlah sesuatu yang baru. Artinya, tradisi cerita mistik atau hantu ini memang mengakar dalam masyarakat. Kepentingan pasar dan kreativitas menjadi alasan terjadinya migrasi ini. Namun, hal yang utama bukanlah persolan itu. Hal yang menjadi perdebatan adalah jumlah, keragaman atau bentuk tata naratif, serta tampilan ataupun sejenis yang muncul dalam aplikasi Playstore. Bentuk dari cerita hantu itu di antaranya adalah game, suara, nada dengar, musik, dan cerita hantu. Dominasi itu muncul dalam cerita hantu, yang mengumpulkan beragam cerita hantu dari berbagai dearah dalam bentuk bacaan yang tidak terlalu panjang. Berikut adalah contoh dari beberapa cerita hantu dalam Playstore.

\begin{tabular}{|c|c|c|c|}
\hline Nama Cerita & Unduhan & Nilai & Keterangan \\
\hline $\begin{array}{l}\text { 1000+ Cerita } \\
\text { Hantu Horor } \\
\text { Terbaru }\end{array}$ & $\begin{array}{l}10000 \text { lebih, } 155 \\
\text { reviews }\end{array}$ & 4,3 & $\begin{array}{l}\text { Aplikasi yang berisi ribuan cerita hantu } \\
\text { seram nyata, menempati ranking } 5 \text { dalam } \\
\text { aplikasi. Cerita yang utama diunggulkan } \\
\text { adalah cerita hantu pocong, kuntilanak, } \\
\text { sundel bolong, genderuwo, arwah } \\
\text { penasaran/gentayangan, teluh, jin, dll. }\end{array}$ \\
\hline $\begin{array}{l}\text { Cerita Hantu } \\
\text { Horor Seram }\end{array}$ & $\begin{array}{l}50.000 \text { lebih, } \\
444 \text { reviewer }\end{array}$ & 4.0 & $\begin{array}{l}\text { Berisi cerita koleksi } 1000+\text { kisah hantu, } \\
\text { cerita seram yang berhubungan dengan } \\
\text { hantu termasuk kuntilanak }\end{array}$ \\
\hline $\begin{array}{l}\text { Suara Hantu: } \\
\text { Pocong } \\
\text { Kuntilanak }\end{array}$ & $\begin{array}{l}10000 \text { lebih, } 99 \\
\text { reviewer }\end{array}$ & 3.8 & $\begin{array}{l}\text { Berisi kumpulan suara mengerikan dari } \\
\text { berbagai hantu di Indonesia, seperti } \\
\text { pocong, kuntilanak, nenek lampir, suster } \\
\text { ngesot, tuyul, genderuwo, dll. }\end{array}$ \\
\hline $\begin{array}{ll}\text { Cerita } & \text { Horor } \\
\text { Seram } & \end{array}$ & $\begin{array}{l}5000 \text { lebih, } 44 \\
\text { reviewer }\end{array}$ & 4.1 & $\begin{array}{l}\text { Menjelaskan asal usul hantu yang } \\
\text { sesungguhnya ada, cerita bersisi } \\
\text { kehidupan hantu yang berusaha } \\
\text { dinyatakan secara ilmiah melalui cerita } \\
\text { misteri. }\end{array}$ \\
\hline $\begin{array}{l}100 \quad \text { Cerita } \\
\text { Hantu Seram }\end{array}$ & $\begin{array}{lr}100.000 & \text { lebih, } \\
1000 & \text { lebih } \\
\text { reviewer } & \\
\end{array}$ & 4.1 & $\begin{array}{l}\text { Berisi tentang cerita hantu yang diambil } \\
\text { dari kisah nyata. }\end{array}$ \\
\hline $\begin{array}{l}\text { Kisah Hantu } \\
\text { Terbaik } 2019\end{array}$ & $\begin{array}{l}100000 \text { lebih, } 93 \\
\text { reviewer }\end{array}$ & 3.8 & $\begin{array}{l}\text { Aplikasi ini bercerita tentang } 50 \text { kisah } \\
\text { seram. Kisah tersebut diambil dari } \\
\text { berbagai sumber di dalam internet dan } \\
\text { berdasarkan pengalaman para sahabat. }\end{array}$ \\
\hline $\begin{array}{l}\text { Ringtone Suara } \\
\text { Kuntilanak } \\
\text { Seram Mp3 } \\
\end{array}$ & $\begin{array}{l}10000 \text { lebih, } 120 \\
\text { reviewer }\end{array}$ & 3.8 & $\begin{array}{l}\text { Aplikasi untuk nada dengar yang berisi } \\
\text { suara kuntilanak }\end{array}$ \\
\hline
\end{tabular}

Received 09-04-2020, Accepted 16-05-2020

https:doi.org/10.26499/bahasa.v2i3.50

Published By: Perkumpulan Pengelola Jurnal Bahasa dan Sastra Indonesia (PPJB-SIP) 


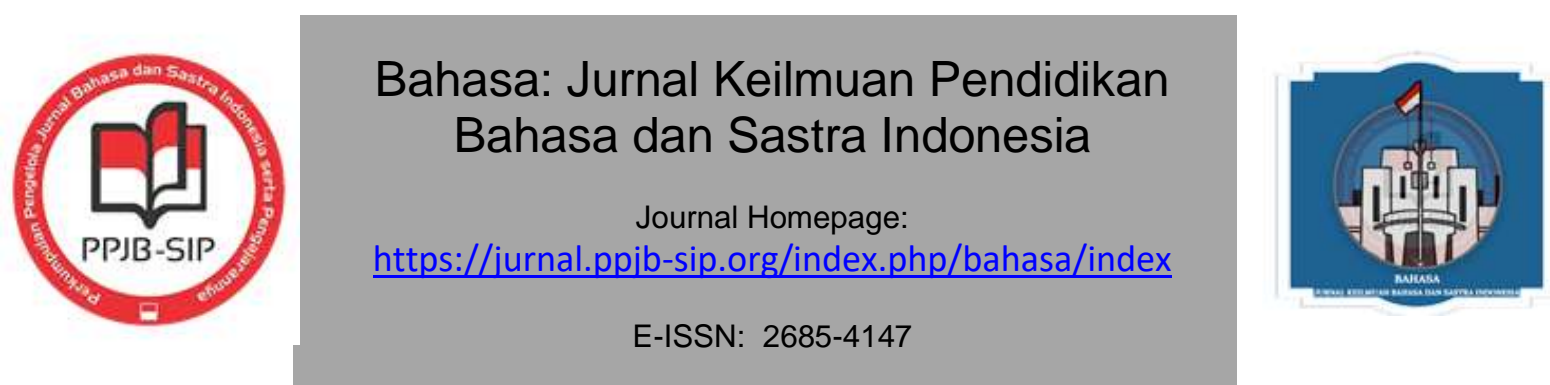

$\begin{array}{llll}\text { Cerita } & \text { Hantu } & 10000 \text { lebih, } 78 & 4.1 \\ \text { Seram } & \text { Nyata } & \text { reviewer } & \end{array}$
2019
Aplikasi ini berisi cerita hantu Indonesia hingga tahun 2019. Cerita ini bersifat mistis, menakutkan, dan berdasarkan kisah yang dialami masyrakat secara supernatural, hantu seram modern, macam-macam hantu daerah, dan lainlain.

Beberapa contoh tersebut menunjukkan bahwa unduhan untuk cerita itu berada di atas sepuluh ribu hingga seratus ribu lebih, yakni $10 \mathrm{~K}+, 5 \mathrm{~K}+, 50+$, dan $100 \mathrm{~K}+$. Sementara itu, reviewer (pembaca atau konsumen) dari aplikasi tersebut menunjukkan angka yang beragam, seperti 44, 78, 99, 155, hingga 444. Hal ini cukup menarik untuk diamati bahwa pengulas ini merupakan pembaca yang memberikan kritik ataupun masukan terhadap isi dari aplikasi. Jadi, dia dapat diasumsikan telah membaca aplikasi tersebut. Sementara itu, nilai bintang untuk tiap aplikasi juga muncul dan berada pada rata-rata nilai 3 lebih, yakni 4.1 dan 3.8.

Berdasarkan data itu, cerita hantu dalam aplikasi mendapat sambutan yang positif dengan jumlah pembaca yang relatif banyak. Sementara, hal yang muncul dalam aplikasi ada yang berbayar dan ada yang gratis. Contoh cerita hantu yang berbayar adalah yang berbentuk film dan e-book. Hal ini sebagai contohnya adalah Hantu: dari Suster Ngesot sampai Sundel Bolong dan beberapa yang lainnya. Buku tersebut dijual dengan harga Rp32.370,00. Iklan buku ini telah dilihat pembaca sebanyak 2000 lebih. Fakta ini menunjukkan bahwa dalam aplikasi Playstore, cerita hantu memasuki ruang hiburan dan komersial.

Sementara itu, dari segi isi, cerita mengenai hantu ini diambil dari berbagai cerita hantu di seluruh Indonesia, terutama dalam khazanah masyarakat Jawa. Hantu dalam masyarakat Jawa muncul sebagai hantu yang paling dominan. Selain itu, ada juga kategori hantu yang hidup dalam pedesan atau tradisi hantu metropolitan. Hantu yang menjadi hantu metropolitan ini mengalami bukan hanya migrasi bentuk dan tempat secara fisik, tetapi hal itu juga migrasi ruang yang bersifat kosmologis dan tradisi.

Sastra hantu ini muncul dalam berbagai bentuk, seperti game, musik, nada dengar, dan bentuk cerita. Namun, hal yang paling dominan adalah dalam bentuk cerita. Umumnya, cerita dalam aplikasi Playstore ini berasal dari berbagai cerita hantu. Cerita hantu dimasakinikan dan disesuaikan dengan latar dan alam kehidupan masa kini, terutama daerah perkotaan. Hal ini menunjukkan migrasi hantu dalam bentuk yang tradisional atau dari daerah desa (terbelakang) menjadi ruang metropolitan, ruang kapitalisme. Latar dan isi cerita juga sudah tidak menampilkan gagasan sebuah daerah misterius yang terpelosok. Migrasi ruang telah membawa pada hantu yang bercita rasa metropolitan. Namun, hal yang paling penting dari tampilan ini bukan gambar, tetapi narasi yang dibangun atas tampilan dan isi cerita. Isi cerita merupakan narasi yang bersifat sederhana, yakni kejadian sang tokoh ketika bertemu dengan hantu. Hal ini 

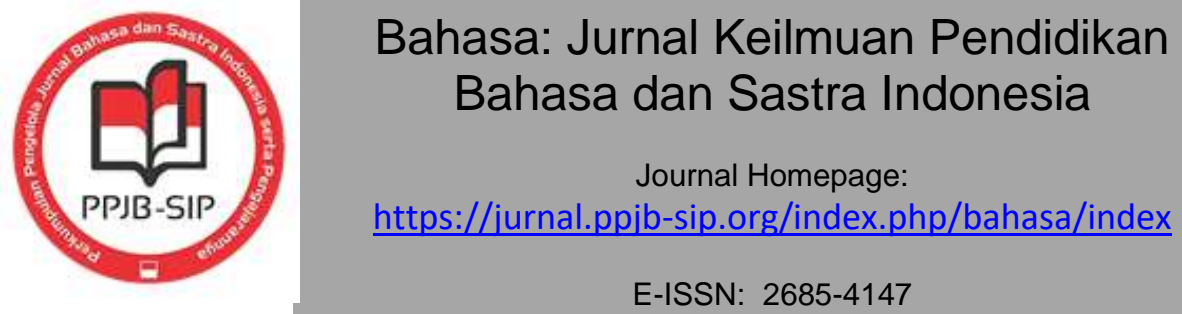

diungkapkan dengan menggunakan bahasa yang ringan dan gaya yang metropolitan. Jumlah kata pun tidak terlalu banyak, sekitar 300 sampai dengan 800-an kata.

Jumlah kata menjadi perhatian yang cukup penting sebab hal ini berhubungan dengan pola konsumsi dari cerita itu. Pembaca atau konsumen memang diarahkan untuk menikmati tulisan ini dalam bentuk yang ringkas dan dengan alur cerita atau tata naratif yang mudah dipahami dan tidak membutuhkan banyak waktu ketika membca. Hal ini dihubungkan dengan "ketersediaan layar" pada perangkat dan habitual membaca melalui perangkat handphone yang cenderung membaca dalam sekilas waktu tetapi mendapatkan banyak informasi. Hal serupa juga berlaku untuk cerita hantu ini. Cerita ini dalam aplikasi berisi tidak hanya beberapa cerita hantu saja, tetapi lebih dari lima puluh hingga ribuan dengan durasi waktu baca atau teks yang tidak membutihkna waktu sekitar empat sampai lima menit untuk setiap ceritanya. Hal ini menjadi perhatian dari pencipta aplikasi untuk membuat tegangan atau tone cerita yang menarik dalam waktu yang singkat.

\section{Respons Pembaca Aplikasi}

Respons pembaca ini dapat diperoleh salah satunya melalui ulasan atau review dari pembaca. Ulasan itu umumnya memberikan tanggapan terhadap apliaksi ataupun isi cerita. Tanggapan itu berjumlah cukup banyak. Ada yang berjumlah 1000+, seperti cerita pada aplikasi "100 Cerita Hantu". Secara umum, mereka merekam tanggapan yang ringkas terhadap isi cerita ataupun reaksi setelah membaca cerita. Selain memberikan tanggapan, mereka juga memberikan penilaian dengan memberikan tanda bintang pada isi cerita tersebut. Berikut contoh tanggapan atas cerita dari aplikasi "100 Cerita Hantu".

\begin{tabular}{lllr}
\hline Nama akun & Komentar & Kategori & \\
\hline Del Yantiho & $\begin{array}{l}\text { Gw Bacany pas tengah malam di rumah, itu } \\
\text { pasti orang tua udh tidur dong kan? Nah pas } \\
\text { udah merinding bacanya, tiba-tiba karsus atas } \\
\text { lemari jatuh }\end{array}$ & $\begin{array}{l}\text { Respons } \\
\text { setelah } \\
\text { cerita }\end{array}$ & $\begin{array}{r}\text { psikis } \\
\text { membaca }\end{array}$ \\
\hline $\begin{array}{l}\text { Ilham } \\
\text { Wahyudi }\end{array}$ & $\begin{array}{l}\text { Aku suka bgt karena bikin merinding dan adds } \\
\text { yang Romantis hahaha }\end{array}$ & $\begin{array}{l}\text { Respons } \\
\text { setelah } \\
\text { cerita }\end{array}$ & psikis \\
\hline Abdul Raof & All the best its story very funny and intersting & $\begin{array}{l}\text { Respons } \\
\text { cerita }\end{array}$ & atas isi \\
\hline Shakila Rosli & $\begin{array}{l}\text { Terlalu banyak kumpulan cerpen horor } \\
\text { didalamnya tapi 60\% ga mutu. Harusnya lebih } \\
\text { selektif dalam memasukkan mana yang layak } \\
\text { tidak menyukai isi } \\
\text { cerita }\end{array}$ & \\
\hline
\end{tabular}

Received 09-04-2020, Accepted 16-05-2020

https:doi.org/10.26499/bahasa.v2i3.50

Published By: Perkumpulan Pengelola Jurnal Bahasa dan Sastra Indonesia (PPJB-SIP) 


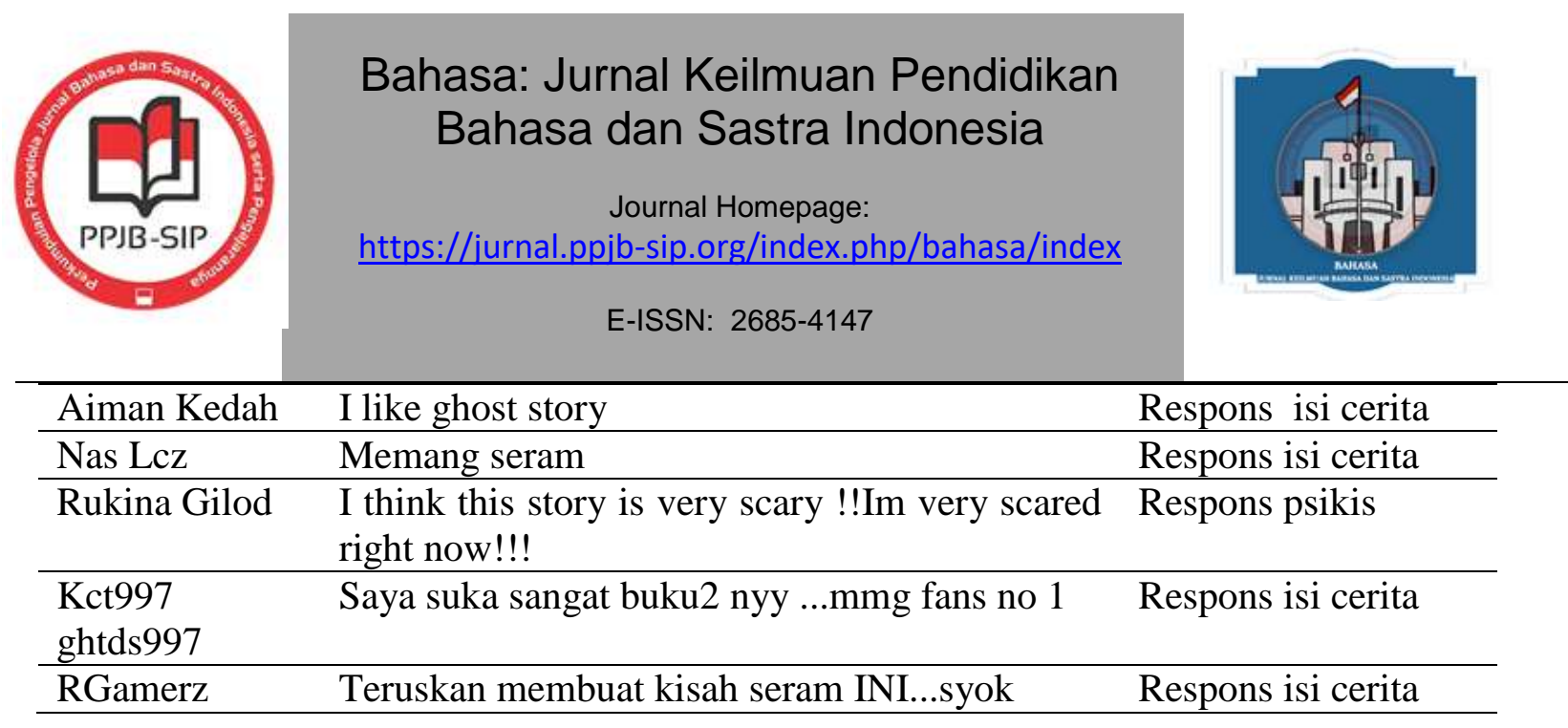

Beberapa contoh respons tersebut menunjukkan bahwa pembaca secara umum menggunakan dua respons, yakni respons terhadap tata naratif cerita dan respons yang bersifat psikologis. Respons yang bersifat negatif umumnya muncul atas dasar ketidaksukaan pada jenis cerita ataupun isi cerita, yakni tata naratif yang dipandang terlalu monoton. Artinya, pembaca tersebut dapat diasumsikan telah mengenal norma-norma kesastraan ataupun horison yang sudah terbiasa. Fakta ini sekaligus menandakan bahwa mereka telah mengenal atau familiar dan menyukai cerita tersebut, meski kesimpulan ini dapat dipertanyakan kembali.

Sementara itu, respons yang bersifat psikologis justru menandakan bahwa mereka menikmati atau mengonsumsi cerita dengan baik. Sebab, dampak yang dirasakan cukup membawa efek dalam diri mereka. Namun demikian, hal yang perlu dijelaskan adalah masalah dampak psikologis. Mereka yang terkena ataupun memberikan respons secara psikologis dapat disimpulkan sementara sebagai penikmat cerita atau dapat dipandang juga sebagai yang belum familiar dengan tata cerita. Namun, hal ini juga dapat diperdebatkan. Sementara itu, mereka yang menilai tata cerita pada hakikatnya lebih tertarik pada cara penyajian cerita sehingga tidak terkena dampak psikologis. Kedua pendapat tersebut pada hakikatnya masih bersifat spekulatif dan perlu ada uji coba dengan melakukan wawancara atas respons tersebut atau eksperimen atas respons terhadap pembacanya.

Dari respons pembaca ini, hal yang lebih penting lagi adalah masalah yang bersifat sosiologis. Artinya, pembaca cerita berjumlah puluhan hingga ratusan ribu. Hal ini menandakan bahwa genre cerita hantu dalam aplikasi memang sangat disukai pembaca. Sebagai bahan bacaan populer dan ringan, pembaca tidak perlu melakukan sebuah upaya yang serius dalam memahami ataupun mengambil hikmah cerita. Genre ini telah bermigrasi dalam bentuk aplikasi dan pembaca mengisi waktu luang yang sesaat dengan membaca cerita-cerita seperti ini. Aspek hiburan atas bahan bacaan dan ketersedian informasi cerita yang singkat dan dalam jumlah yang banyak ini menjadi bagian dari pasar yang harus dipenuhi penyedia aplikasi atau mereka yang bergerak dalam dunia literasi virtual, seperti sebuah penyedia jasa permaian atau game virtual (Haramban, Auspers, \& Houtman, 2011:291-292).

Bila fakta ini dibandingkan dengan jumlah pembaca "sastra yang dikanonkan" atau "sastra serius" dalam media cetak, perbandingan tersebut tidak setara. Artinya, hasil penjualan

Received 09-04-2020, Accepted 16-05-2020

https:doi.org/10.26499/bahasa.v2i3.50

Published By: Perkumpulan Pengelola Jurnal Bahasa dan Sastra Indonesia (PPJB-SIP) 

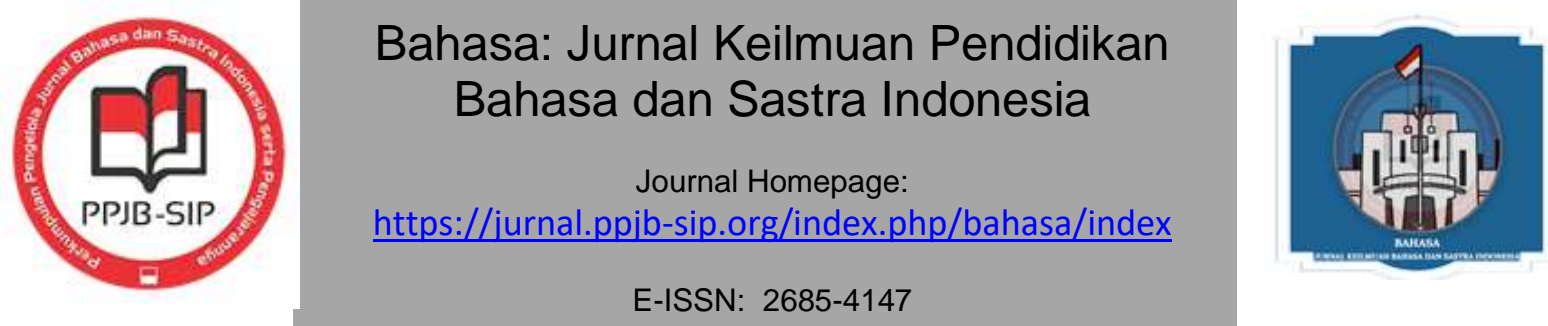

buku dengan unduhan aplikasi tentu berbeda. Hal ini selain karena faktor ekonomi dan sosiologis lainnya, pembaca lebih menyukai cerita yang mungkin dipandang "tidak bermutu" dan "tidak memiliki estetika" yang disyaratkan oleh ideologi dan pemikiran tertentu dalam kesastraan Indonesia. Sebagai bagian dari bacaan populer, mereka membuat sebuah tata naratif yang dapat disukai oleh para pembacanya. Sebab, persaingan antara pemilik aplikasi atau pembuat cerita ini juga patut dipertimbangkan.

Dari sisi tata naratifnya, cerita ini akan sama dan memiliki pola yang seragam dengan bahan yang sama. Mereka dapat mengambil secara kompilasi dari sumber-sumber virtual yang lain, seperti laman dan lain-lain. Mereka juga membuat cerita komentar atas cerita yang sudah ada. Masalah hak cipta dan orisinalitas cerita bukan lagi menjadi ukuran dari keberhasilan karya atau nilai estetika. Berbagai cerita yang tumpang tindih dan bercampur menjadi satu dalam aplikasi ini. Komentar sebuah wacana yang satu dibangun atas ", apakah cerita itu berkualitas estetika kanon, dari mana asal cerita, apakah penulisnya plagiat, dan lain-lain. Bagi mereka, tuntutan yang harus dipenuhi adalah memberikan efek kesenangan dan hiburan pada pembaca.

Sementara itu, dari sisi sosiologis, berdasarkan pada respons pembaca, hal yang perlu diperhatikan oleh pembuat cerita adalah menyediakan aspek kemudahaan dan kecepatan. Kemudahan dan kecepatan dalam proses unduh dan membaca cerita yang tidak terlalu sulit secara teknis hingga tidak memerlukan waktu yang lama, cukup dua atau tiga detik sudah terhadirkan cerita yang siap untuk dibaca. Kemudahan dan kecepatan dalam mencerna dan membaca isi cerita ataupun teks cerita. Mereka menginginkan sebuah transformasi kecepatan dalam membaca dan mencerna bermacam-macam informasi. Jadi, semakin ringkas atau pendek dan memuat berbagai informasi yang beragam sebuah cerita, pembaca akan semakin suka. Hal ini menjadi satu ciri dari generasi $\mathrm{Z}$ yang menginginkan kecepatan, kemudahan, efektivitas, dan tidak menyukai sesuatu yang merepotkan.

\section{Produksi Simbolik; Misteri dan Estetika Resistensi}

Migrasi cerita hantu dalam masyarakat digital ini tampaknya tidak lagi membawa persoalan pada ruang dan waktu. Artinya, bila dulu migrasi ini dapat dikategorikan sebagai bentuk migrasi metropolitan secara lokasi, kini hantu menjadi makhluk metropolitan dan tradisional sepenuhnya. Sebab, akses dan isi cerita bercampur jadi satu. Namun, hal yang paling dominan dari isi cerita itu adalah hantu yang bermetaformosis menjadi hantu modern, hantu kota, ataupun hantu metropolitan. Fakta ini sekaligus memberikan bukti bahwa telah terjadi perubahan atas estetika naratif cerita hantu. Hal ini ditunjukkan dengan kenyataan bahwa hantu yang muncul dalam cerita itu adalah hantu kekininan dan hantu dalam kehidupan milenial atau digital. Mereka adalah pocong, suster ngesot, kuntilanak, dan tuyul yang bertransformasi dalam dunia kekinian.

Fakta yang menarik dari keadaan itu adalah sebuah estetika misteri yang hendak dikonstruksikan. Misteri dalam konteks ini tidak lagi menjadi sebuah cerita yang berhubungan

Received 09-04-2020, Accepted 16-05-2020

https:doi.org/10.26499/bahasa.v2i3.50

Published By: Perkumpulan Pengelola Jurnal Bahasa dan Sastra Indonesia (PPJB-SIP) 

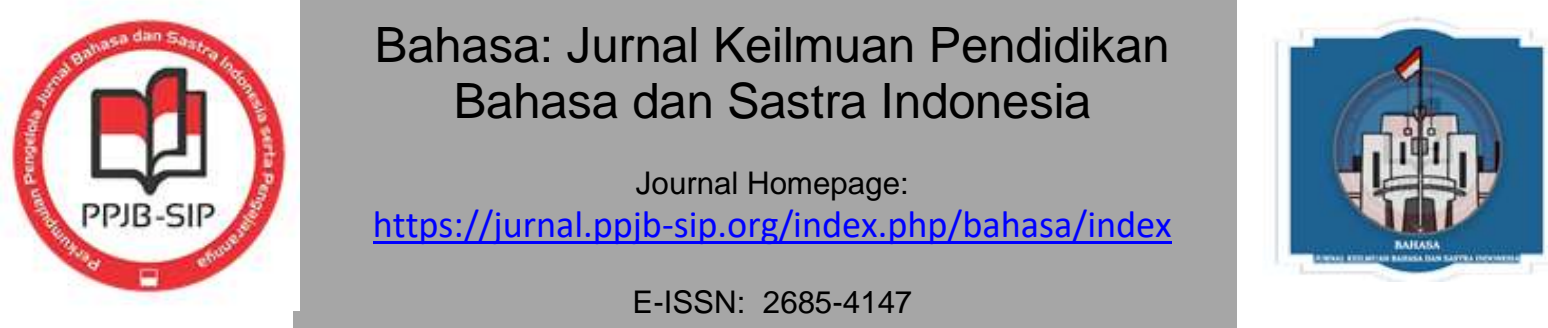

dengan dunia lampau dan bentuk-bentuk pengungkapan atau eskpresi tardisional. Misteri dalam wujud hantu pada mulanya sebuah genre yang berasal dari lingkungan tradisional, pedesan, udik, dan memilik konotasi ketertinggalan atau keterbelakangan mental dan kebudayaan. Misteri dalam wujud hantu tersebut menjadi sebuah kelainan dan keanehan yang patut diadabkan melalui proses modernisasi atau "akal pikiran". Misteri bahkan dianggap sebagai sebuah wacana tentang keterasingan, ganguan psikologis, kebodohan, kemunduran akal, hingga sebuah warisan yang patut dijadikan alasan atau landasan untuk membuat kateoti atara yang berakal dan yang tidak berakal atau yang modern dan yang dalam kegelapan.

Namun, kini misteri melalui genre cerita hantu menjadi sesuatu yang berbeda, yakni sebuah reproduksi misteri yang baru. Reproduksi misteri yang baru ini dapat diwujudkan melakui kehadiran hantu dalam dunia modern atau era digital. Hantu kini menembus batas-batas antara yang tradisional dan yang modern. Batas keduanya tidak ada lagi dan tidak muncul oposisi yang demikian. Sebab, hantu yang dulu menjadi bagian dari "yang lain" atau "yang terbelakang", kini hantu menjadi bagian yang intergral dari "yang maju" dan "yang berakal". Artinya, perbedaan antara yang berakal dan tidak berakal atau mistis tidak ada lagi. Oposisi yang demikian sudah mencair dan hilang dengan sendirinya.

Fakta tersebut dapat dibuktikan dalam dua hal. Pertama adalah wujud fisik dari kehadirannya. Kedua adalah isi ceritanya. Keduanya dinikmati sebagai hiburan dan tidak lagi dipercayai sebagai sesuatu yang "benar-benar terjadi" meski cerita ini menandakan adanya petanda "benar-benar pernah terjadi". Logika dan akal pikiran tampaknya tidak memainkan peran yang penting dalam menilai dan membaca cerita ini. Meski tanggapan menunjukkan rasa takut, tetapi mereka tetap saja menyukai dan membacanya. Artinya, kebutuhan akan cerita hantu itu bukan lagi sebagai sebuah citra masyarakat atau representasi alam pikiran, melainkan representasi yang menolak gagasan yang dulu pernah dihadirkan oleh estetika ini melalui genre cerita hantu.

Misteri yang dibangun bukan lagi sebuah misteri yang tercitra dalam tradisi estetika masa lalu. Melalui isi, tampilan, dan respons pembaca, misteri bukan lagi sebagai sesuatu yang menakultkan dan dihindari. Namun, respons pembaca dan tampilan sastra virtual menunjukkan misteri dalam genre hantu ini adalah sesutau yang dicari dan misteri sebagai sebuah kenikmatan atau kesenangan. Hal ini terbukti dari jumlah unduhan, komentar, reviewer, dan tampilan hingga tata naratif. Jadi, secara sederhana reproduksi misteri tersebut menjadi sebuah misteri yang bukan menakutkan atau tradisional, melainkan misteri sebagai suatu kesenangan dan modern atau diterima dalam alam modern atau kekininan. Dia hadir barangkali sebagai olok-olokan, kerinduan, ataupun sekadar kesenangan sesaat, bahkan menjadi informasi yang sangat dibutuhkan oleh masyarakat kekinian.

Perubahan simbolik dari makna misteri ini juga membawa konsekuensi pada perubahan lainnya. Hal ini terutama pada estetika yang dibangun oleh genre tersebut melalui migrasi dalam media virtual. Berdasarkan pada tampilan, jumlah unduhan, dan komentar pembaca serta jumlah 

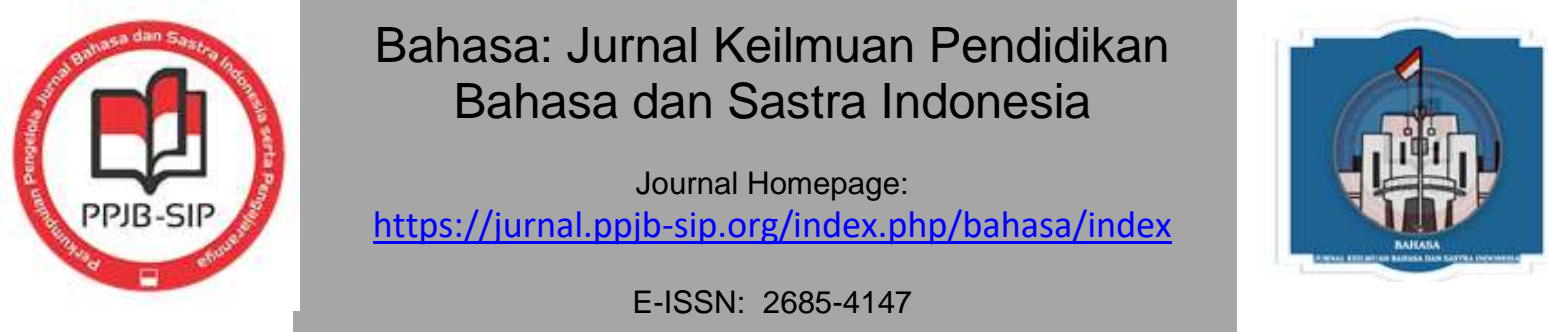

persebaran cerita hantu itu, estetika yang dibangun oleh genre tersebut adalah estetika perlawanan. Estetika perlawanan itu ditunjukkan dengan sebuah upaya untuk menolak gagasan dominan lainnya, terutama ada beberapa hal, yaituestetika kesastraan yang dominan atau kanonik, reprentasi genre atau estetika cerita misteri, ataupun representasi kekinian masyarakat yang sudah sulit dipisahkan antara yang real dan yang bukan.

Kehadiran cerita hantu dalam aplikasi merupakan sebuah perlawanan terhadap estetika kanon kesastraan dalam sastra Indonesia. Dia hadir melalui genre misteri yang berbeda dengan sastra-sastra yang dilembagakan. Namun, dia mampu menembus batas pembaca dan ruang estetik. Hal ini dibuktikan dengan jumlah pembaca, respons pembaca, dan keragaman cerita. Memang, cerita itu tidak pernah masuk ke dalam wacana pembahasan sastra atau estetika. Kalau pun masuk ke dalam pembahasan estetika, genre tersebut berada dalam ruang pinggiran atau terdegradasi dalam konteks kesastraan "sesungguhnya". Sebagai akibatnya, kehadiran teks atau genre tersebut pada hakikatnya ingin meruntuhkan oposisi antara sastra terlembagakan atau serius versus sastra populer atau terpinggirkan, ataupun lebih lanjut mengubah suatu pandangan antara sastra versus bukan sastra.

Selain gagasan tersebut, kehadiran cerita misteri atau genre hantu juga mulai mengubah genre itu. Cerita hantu pada mulanya adalah cerita yang terpinggirkan, mistik, dan bukan menjadi bagian dari kesastraan kanon. Cerita itu berada dalam ruang terpinggirkan, tradisional, dan bahkan tidak pernah diperhitungkan kehadirannya dalam kesastraan atau wacana estetika pada umumnya. Namun, kini dia telah bertranformasi, memasuki dunia digital dan mengubah citra cerita melalui isi dan tampilan. Cerita itu dikonsumsi oleh semua kalangan dan lapisan, dari usia hingga pendidikan. Fakta ini sekaligus menunjukkan bahwa cerita itu berusaha mendefinisikan ulang "estetika" yang melabelinya dulu. Cerita hantu itu berada dalam jalur "keterbelakangan", tetapi kini memasuki wilayah metropolitan. Artinya, kehadirannya justru menjadi bagian dari upaya redefinisi tersebut.

Selain itu, cerita hantu dalam aplikasi ini berusaha membuat sebuah gagasan tentang oposisi yang nyata versus nyata. Hal ini dibuktikan dengan konstruksi isi teks dan tampilan teks yang mengemukan bahwa hantu memang ada dan menjadi bagian dari makhluk ciptaan Tuhan. Selain itu, sebagai mahluk yang patut dipercayai keberadaannya, sisi naratif cerita hantu dalam aplikasi ini juga menunjukkan bahwa cerita tersebut seakan-akan "benar-benar terjadi atau dialami”. Hal ini menandakan ada upaya menjadikan hantu sebagai reproduksi perlawanan atas konsep "hantu" pada masa dulu. Dulu, dalam kanon sastra, cerita misteri hanya sebuah karangan atau lamunan yang bertujuan menakuti saja. Namun, kini, cerita hantu seakan-akan dialami dan telah migrasi pada kehidupan era kosmopolitan..

\section{KESIMPULAN}

Genre cerita hantu atau misteri memiliki tampilan yang menunjukkan sebuah migrasi dari yang tradisional menuju metropolitan. Hal ini sekaligus sudah menandakan adanya Received 09-04-2020, Accepted 16-05-2020

https:doi.org/10.26499/bahasa.v2i3.50

Published By: Perkumpulan Pengelola Jurnal Bahasa dan Sastra Indonesia (PPJB-SIP) 

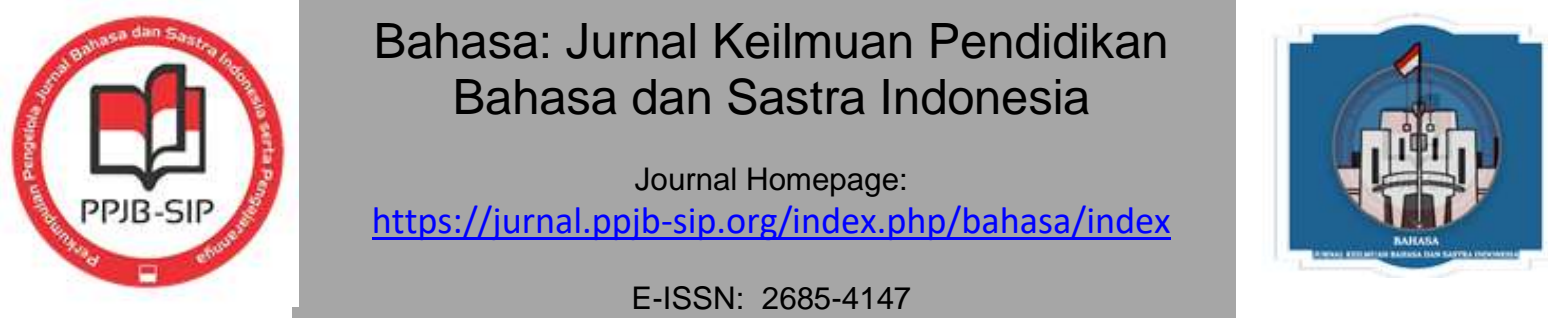

konstruksi konsep estetika dalam wacana kesastaraan. Sementara itu, respons pembaca menunjukkan sebuah kecenderungan tentang penerimaannya sebagai bukan genre misteri yang menakutkan, tetapi telah berubah ke wilayah hiburan atau humor. Hal ini serupa dengan tampilan tata naratifnya. Kedua menunjukkan sebuah upaya untuk kembali kepada gagasan perlawanan. Hal itu dilakukan dengan menciptakan simbol yang baru atas genre tersebut, misalnya melalui tampilan, tata naratif, dan migrasi gagasan cerita.Sementara itu, genre cerita hantu ini juga telah melakukan reproduksi simbol terutama pada gagasan tentang misteri dan perlawanan. Sebagai bagian dari perlawanan, cerita hantu membongkar gagasan tentang genre misteri dalam estetika kesastraan. Kehadirannya yang terpinggirkan dalam wacna kesastraan berusaha diubah menjadi bagian yang wajar dan diterima oleh kalangan masyarakat, dari yang tradisi menjadi metropolitan.

\section{DAFTAR PUSTAKA}

Becker, Howard. (1974). “Arts as Collective Action”, American Sociological Review, Vol. 39, No. 6 1974, hlm. 767-76

Bok, C. (2011). The Xenotext Works. Harriet: The Blog. Avaible at: http://www.poetryfoundation.org/herriet/2011/04/the-xenotext-works/ (Accessed December 20, 2017)

Bouchardon, Serge dan Asucion Lopez-Varela. (2011). "Making Sense of the Digital as Embodied Experience", CLCWeb: Comperative Literature and Culture, Vol. 13, No. 3, 2011, http://dx.doi.org/10.7771/1481-4374.1793

Haramban, Jaron, Aupers, Stef, \& Houtman, Dick. (2011). "Game Over? Negotiating modern capitalism in virtual game worlds", European Journal of Culture Studies, 14 (3) 2011, hlm. 299-319

Herfanda, Ahmadun Yosi. (2004). "Puisi Cyber, Genre atau Tong Sampah”, Situmorang, Saut (ed.). Cyber Graffiti: Polemik Sastra Cyberpunk. Yogyakarta: Jendela

Hock, Michel. (2004). "Virtual Chinese Literature: A Comperative Case Study of Online Poetry Communities", paper IIAS, October 2004

Mawardi, Arif Budi. (2018). "Komodifikasi Sastra Cyber Wattpad pada Penerbit Indie”, Sabda Vol. 13, No. 1, Juni 2013, hlm. 77-82

Septriani, Hilda. (2016). "Fenomena Sastra Cyber: Sebuah Kemajuan atau Kemunduran?. , makalah Seminar Nasional Sosiologi Sastra di Fakultas Ilmu Pengetahuan Budaya, Universitas Indonesia, 10-11 Oktober 2016

Supriatin, Yeni Mulyani. (2012). "Kritik Sastra Cyber”, Jurnal Sosioteknologi Edisi 25 Tahun 11, April 2012, hlm. 47-54

Wolff, Janet. (2005). "Cultural Studies and the Sociology of Culture" David Inglis \& John Hughson. (Ed). The Sociology of Art Ways of Seeing. New York: Palgrave macmillan, hlm. 87-97

Received 09-04-2020, Accepted 16-05-2020

https:doi.org/10.26499/bahasa.v2i3.50

Published By: Perkumpulan Pengelola Jurnal Bahasa dan Sastra Indonesia (PPJB-SIP) 


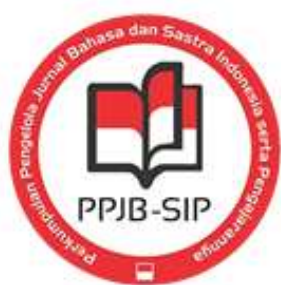

Zalbeida, Maya \& Sotelo, Xiana. (2014). "Electronic Literature and the Effects of Cyberspace on the Body" CLCWeb" Comperative Literature and Culture, Vol 16 Issue 6, 2014 $<$ https://doi.org/10.7771/1481-4374.2489 